\title{
Fecal microbiota transplantation in hepatic encephalopathy : a review of the cur- rent evidence and future perspectives
}

\author{
E. Afecto, A. Ponte, S. Fernandes, J. Silva, C. Gomes, J. Correia, J. Carvalho \\ Department of Gastroenterology, Centro Hospitalar Vila Nova de Gaia Espinho, Portugal.
}

\begin{abstract}
Hepatic encephalopathy (HE) is a leading cause of hospitalization and morbimortality in advanced cirrhosis with limited therapeutic options available. Given the paramount role of gut microbiota in $\mathrm{HE}$, and the efficacy of fecal microbiota transplantation (FMT) in other diseases, this review intends to summarize the evidence supporting the safety, efficacy and future perspectives of FMT in HE. Current evidence, despite being scarce, points towards FMT being a safe, effective and tolerable procedure in HE. Some unanswered questions remain about the optimal dose, the administration route, the long term effects and the selection of the optimal donor. Future trials, some of which are already underway, will provide us additional evidence and hopefully the necessary answers. (Acta gastroenterol. belg., 2021, 84, 87-90).
\end{abstract}

Keywords : Hepatic encephalopathy, fecal microbiota transplantation, gut microbiome, cirrhosis.

\section{Introduction}

Hepatic encephalopathy (HE) is one of the leading causes of hospitalization and one of the most debilitating complications of cirrhosis or portosystemic shunting, affecting the quality of life of both patients and caregivers. Additionally, it is associated with a significant healthcare financial burden due to cognitive impairment and repeated hospitalizations (1).

Overt HE occurs in up to $14 \%$ of patients by the time of the diagnosis of cirrhosis, increasing up to $21 \%$ in decompensated cirrhosis. The cumulative incidence of overt $\mathrm{HE}$ is $40 \%$ during the clinical course of the disease, often relapsing (1). The mortality of HE is around $5-27 \%$ during hospitalization, increasing up to $50 \%$ at one year of follow-up $(2,3)$.

Although the pathogenesis of HE isn't completely understood and is probably multifactorial, there is growing evidence supporting a central role of gut microbiota. In cirrhosis, a reduction of beneficial commensal bacteria (ex : Ruminococcaceae and Lachnospiraceae) and an increase of non-autochthonous bacteria (ex : Streptococcaceae and Enterobacteriaceae) has been previously demonstrated $(4,5,6)$. This results in a microbiome imbalance known as "cirrhosis dysbiosis ratio", which is associated with an increased model for end stage liver disease (MELD) score (5). It is believed that ammonia, a neurotoxin produced by urease-containing bacteria, through a combination of decreased metabolism in the diseased liver, decreased skeletal muscle clearance and portosystemic shunting, penetrates the blood-brain

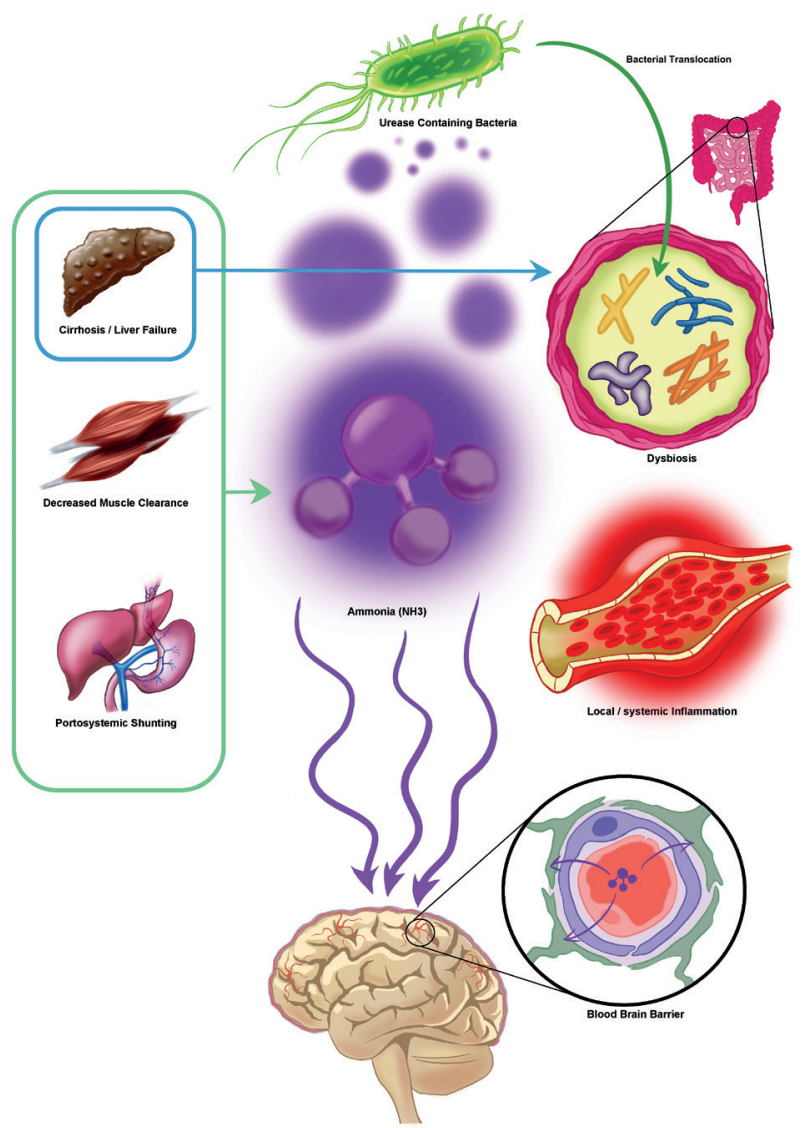

Figure 1. - Gut-liver-brain axis and hepatic encephalopathy

barrier and is the main contributing factor for HE. There is also a role for local and systemic inflammation and endotoxinemia, precipitated by bacterial translocation $(7,8)$. These mechanisms are outlined in figure 1 . The gut-liver axis results in a complex interaction between liver function and gut microbiome and is fundamentally altered in cirrhosis. One of the proposed main mechanisms of dysbiosis is the decrease of bile acid production (due to liver insufficiency), which in turn has a direct effect over gut microbiome, favoring non-autochthonous

Correspondence to : Edgar Manuel Pontes Afecto, Centro Hospitalar Vila Nova de Gaia Espinho, Department of Gastroenterology, Rua Conceição Fernandes, 4434-502, Vila Nova de Gaia, Portugal. Phone +351 913124 443. Fax : +351 227830209.

E-mail: edgarafecto@gmail.com

Submission date : 27/07/2020

Acceptance date : 09/10/2020 
bacteria. Other factors such as diet, inflammation, portal hypertension and drugs (antibiotics and proton pump inhibitors) also play a part in dysbiosis. On the other hand, the "good" bacteria are critical in maintaining an intact gut barrier and reducing bacterial translocation associated with advanced cirrhosis $(7,9)$.

The current standard of care (SOC) treatment for $\mathrm{HE}$ are non-absorbable disaccharides (lactulose and lactitol) and non-absorbable antibiotics (rifaximin) (1). Non-absorbable disaccharides work through several mechanisms, such as reducing the absorption of ammonia due to a direct laxative effect and by acidifying the colon, but also working as a pre-biotic, allowing for the proliferation of non-urease containing commensal bacteria, which metabolize these disaccharides into short-chain fatty acids. Rifaximin reduces pathological bacteria load but also changes their virulence and behavior to more beneficial effects $(8,7)$.

Fecal microbiota transplantation (FMT) is a highly effective therapy in recurrent Clostridium difficile infection $(10,11,12)$. It is currently under investigation in other diseases in which gut microbiota also has a pivotal role such has irritable bowel syndrome $(13,14,15)$, intestinal colonization by multi-drug resistant microorganisms $(16,17,18)$ or ulcerative colitis (19) with promising results.

Given the current evidence of the paramount role of gut microbiota in $\mathrm{HE}$ and the limited therapeutic options available that already target the gut microbiome, the purpose of this review is to summarize the available evidence supporting the safety, efficacy and future perspectives of FMT in HE.

\section{Efficacy of FMT in HE}

The first case report of FMT in HE was published by Kao et al (20) in 2015. This case reports a patient with grade I-II (West-Haven criteria [WHC]) HE previously treated with lactulose and rifaximin. As the patient could no longer afford rifaximin, a FMT delivered by enema from an unrelated donor was proposed. The patient performed 4 sessions on a weekly basis, with marked improvement in subjective and objective parameters but relapsing to baseline at week 14 . This data suggested a beneficial but transient effect of FMT in HE. Other case report (21) available only as an abstract described a patient with refractory WHC grade $4 \mathrm{HE}$, despite SOC treatment. He was treated with a daily FMT (healthy family member donor), by enema, for 5 days, with complete improvement of HE. Unfortunately, no followup was described. No information was provided on the volume of FMT used on both case reports.

In a case series (22), 10 patients with WHC grade IIIV recurrent $\mathrm{HE}$, treated with SOC therapy for HE, were subjected to FMT via colonoscopy after 5 days of broad spectrum antibiotics. No information on FMT volume was reported. Healthy donors, selected by the patient or their caregivers, were screened and treated with single dose albendazole prior to donation. Sustained clinical response at week 20 was observed in 6 patients, with no recurrence of HE. Furthermore, a decrease in median MELD score (18 vs. $15 ; \mathrm{p}<0.01)$ and median ChildPugh score $(9.5$ vs. $8 ; \mathrm{p}<0.01)$ was observed in this cohort. Microbiota changes were not analyzed and no information on long term follow-up was provided.

The first randomized, open-label trial was published by Bajaj and colleagues in 2017 (23). In this trial, a single non-related donor was rationally selected to have higher relative abundance of beneficial commensal bacteria, namely Lachnospiraceae and Ruminococcaceae. All patients enrolled were under SOC treatment for HE and proton pump inhibitors, which they maintained for the duration of the trial. A total of 20 patients with similar baseline characteristics were randomized to a SOC arm and a SOC plus a single FMT ( $90 \mathrm{~mL}$ by enema) arm, each one with 10 patients. The follow-up was 5 months. All FMT patients received broad spectrum antibiotics for 5 days previous to the procedure (discontinued $12 \mathrm{~h}$ before FMT). The primary endpoint was safety (compound endpoint of death, hospitalizations, emergency room visits or infections) and secondary endpoints were cognitive function, MELD score and microbiota changes. At the end of follow-up, there was a significant difference in HE episodes between both groups ( 0 in FMT vs. 6 in SOC; $\mathrm{p}=0.03$ ). There was significant improvement in cognitive function in the FMT group compared to baseline (Stroop test $\mathrm{p}=0.04$ and psychometric hepatic encephalopathy (PHES) score $\mathrm{p}=0.01)$ ). There were no significant differences in MELD scores between groups. A relative increase in Lachnospiraceaeae and Ruminococcaceae was observed in the FMT arm compared to the SOC arm. The previous findings were further expanded (24) by increasing the follow-up of these patients for at least 12 months and up to 15 months. The authors reported an acceptable long-term safety profile for the FMT group. There were significantly less hospitalizations ( 10 vs $1 ; \mathrm{p}=0.05$ ) and HE events ( 8 vs $0 ; \mathrm{p}=0.03$ ) in the SOC plus FMT arm. Cognitive function remained significantly better in the FMT group. Although these results are very promising, this study has some important limitations, namely pre-treatment with antibiotics which also influence the microbiome, leading to a possible bias of the precise role of FMT; optimal dosing, donor selection and delivery methods for FMT in HE are still unknown as there is insufficient data, which might limit the generalization of this study; absence of placebo control group with sham FMT; small sample size including patients with a relatively preserved liver function.

More recently, a randomized and placebo-controlled trial (phase 1) was published by Bajaj et al. (25) with a study design similar to the abovementioned randomized trial. Patients with recurrent HE under SOC treatment and MELD score $\leq 17$ were enrolled. A single nonrelated donor was used and the FMT delivery method to the patients consisted in oral capsules (single ingestion 
Table 1. - Ongoing registered clinical trials of fecal microbiota transplantation in hepatic encephalopathy (www.clinicaltrials.gov)

\begin{tabular}{|c|c|c|c|c|c|}
\hline NCT number & Study arms & Study design & Primary endpoint & Patients, $\mathrm{n}$ & Follow-up \\
\hline NCT03796598 & $\begin{array}{l}\text { I - Capsule+Enema FMT } \\
\text { II - Capsule FMT+Enema placebo } \\
\text { III - Capsule placebo+Enema FMT } \\
\text { IV - Capsule+enema placebo } \\
\text { Once, day } 30\end{array}$ & $\begin{array}{l}\text { Randomized, controlled, double } \\
\text { blinded }\end{array}$ & Serious adverse events & 100 & 6 months \\
\hline NCT03420482 & $\begin{array}{l}\text { I - Capsule FMT } \\
\text { II - Capsule placebo } \\
\text { Day } 1,2,7,14,21\end{array}$ & $\begin{array}{l}\text { Randomized, controlled, double } \\
\text { blinded }\end{array}$ & $\begin{array}{l}\text { Cognitive performance } \\
\text { (measured by PHES) at } \\
\text { week } 4\end{array}$ & 30 & 8 weeks \\
\hline NCT03439982 & $\begin{array}{l}\text { I - Enema FMT } \\
\text { Week } 0,1,2,3,4 \\
\end{array}$ & Phase 1 and 2 unblinded trial & $\begin{array}{l}\text { Time until overt HE after } \\
\text { intervention }\end{array}$ & 30 & 9 weeks \\
\hline NCT02255617 & $\begin{array}{l}\text { I - Enema FMT } \\
\text { Week } 0,1,2,3,4\end{array}$ & Phase 1 and 2 unblinded trial & $\begin{array}{l}\text { Time until overt HE after } \\
\text { intervention }\end{array}$ & 4 & 6 months \\
\hline NCT04155099 & $\begin{array}{l}\text { I - High dose lyophilized capsule FMT } \\
\text { II - Low dose lyophilized capsule FMT } \\
\text { III - Placebo capsule } \\
\text { Twice/week, } 4 \text { weeks }\end{array}$ & $\begin{array}{l}\text { Randomized, controlled, double } \\
\text { blinded }\end{array}$ & $\begin{array}{l}\text { Cognitive performance } \\
\text { (measured by Stroop test) } \\
\text { at } 1 \text { month }\end{array}$ & 75 & 12 months \\
\hline NCT02862249 & $\begin{array}{l}\text { I - FMT via gastroscopy } \\
\text { II - Placebo via gastroscopy }\end{array}$ & Randomized, single blinded & $\begin{array}{l}\text { Safety, tolerability and } \\
\text { feasibility }\end{array}$ & 32 & 18 months \\
\hline
\end{tabular}

of 15 capsules), while the control group received placebo capsules. The primary outcomes were safety and tolerability of FMT (determined by serious adverse events, requiring hospitalization) and secondary outcomes were other adverse events (not requiring hospitalization), changes in microbiota, changes in cognitive function and inflammation markers. A total of 20 patients were enrolled, with similar baseline characteristics, half in each group, as the authors calculated this sample had enough power to test safety outcomes. At the end of the follow-up period (5 months), there were less serious adverse events $(n=11$ vs. $n=1, p<0.05)$ and less HE events $(n=7$ vs. $n=1$, $\mathrm{p}>0.05)$ in the FMT arm compared to the placebo arm. Notably, the HE event in the FMT group was considered unrelated, as it occurred after a transjugular intra-hepatic portosystemic shunt procedure. Although this study was not powered for FMT efficacy, a trend of decreased hospitalizations and decreased severe adverse events was observed for the FMT arm. Patients in the FMT arm had an improvement in the cognitive function as objectively assessed with the increased results in the Stroop test at the end of the study compared to baseline. This outcome was not observed in the placebo arm. Patients in the FMT group had higher Lachnospiraceae compared to placebo. When analyzing duodenal mucosa, the FMT group had a higher concentration Ruminococcaceae and Bifidobacteriaceae and a reduction in Streptococaceae and Veillonellaceae, when comparing pre and post FMT. These changes in microbiota were accompanied by decreased intestinal inflammation. Nevertheless, this study also had several limitations : the small sample size limited the conclusions about the efficacy of the oral route for FMT ; rifaximin was not discontinued, which might affect the conclusions about FMT; lastly, all patients were on proton-pump inhibitors, a medication known to influence gut microbiota.

\section{Safety of FMT in HE}

Short term safety data for FMT is already available in the setting of recurrent Clostridium difficile treatment (12), even in immunocompromised patients (26). In this setting, most adverse events reported were mild and self-limited. In HE, the data presented in both studies by Bajaj JS $(23,25)$ seems reassuring regarding short-term safety. Of the 20 patients included in both studies, only one developed a severe adverse event. Nevertheless, it was considered unrelated to FMT by an independent assessment team. Despite the promising results and the currently known safety of FMT performed in other settings, more evidence from randomized controlled trials is warranted to determine the safety of FMT in HE.

Long term safety data for FMT is still lacking and there is concern that gut microbiota may transfer unknown infectious pathogens or even induce chronic diseases phenotypes, including obesity, diabetes, colon cancer, irritable bowel syndrome, etc (12). In order to limit these unwanted effects, stringent donor selection protocols must be adapted (27). Although we already have some data on follow-up for 12-15 months (24), more evidence and larger cohorts with longer follow-up are sorely needed.

\section{Ongoing studies and future perspectives}

Currently, there are several ongoing studies in this area, as summarized in table 1.

Several questions still need to be answered regarding FMT in the setting of recurrent HE despite SOC treatment, such as the optimal dose and administration route, long term effects of FMT, the need for antibiotics previously to FMT to facilitate engraftment and the need for a donor selection based on their microbiota profile. Hopefully, ongoing and future trials will answer these questions. 


\section{Conclusion}

Despite current SOC treatment in overt HE, some patients develop recurrent episodes and need further therapies to control symptoms and improve their quality of life. Thus far, the available evidence for FMT in HE shows promising results as it constitutes a safe, effective and tolerable procedure in these patients. Nevertheless, more evidence is warranted to support these preliminary results.

\section{Acknowledgment}

The authors would like to thank Gonçalo Torres for the conceptualization and design of the illustration in this article.

\section{Financial support}

No funding or writing assistance was provided for this article.

\section{Conflicts of interest}

The authors report no conflicts of interest.

\section{Search strategy and selection criteria}

References for this Review were identified through searches of PubMed, Cochrane and Clinicaltrials.gov with the search terms "fecal microbiota transplantation", "FMT" and "hepatic encephalopathy". Only papers published in English were reviewed. The final reference list was generated on the basis of originality and relevance to the broad scope of this Review.

\section{References}

1. VILSTRUP H, AMODIO P, BAJAJ J, CORDOBA J, FERENCI P, MULLEN K. et al. Hepatic encephalopathy in chronic liver disease : 2014 Practice Guideline by the American Association for the Study of Liver Diseases and the European Association for the Study of the Liver. Hepatology, 2014, 60 : 715-735.

2. CORDOBA J, VENTURA-COTS M, SIMÓN-TALERO M, AMORÓS A, PAVESI M, VILSTRUP H. et al. Characteristics, risk factors and mortality of cirrhotic patients hospitalized for hepatic encephalopathy with and without acute-on-chronic liver failure (ACLF). Journal of Hepatology, 2014, 60 : 275-281.

3. BAJAJ J, O'LEARY J, TANDON P, WONG F, GARCIA-TSAO G, KAMATH P. et al. Hepatic Encephalopathy Remains an Important Independent Determinant of Mortality in Cirrhosis : A Multi-Center NACSELD Experience. Clinical Gastroenterology and Hepatology, 2016, $15: 565-574$.

4. BAJAJ J, HYLEMON P, RIDLON J, HEUMAN D, DAITA K, WHITE M. et al. Colonic mucosal microbiome differs from stool microbiome in cirrhosis and hepatic encephalopathy and is linked to cognition and inflammation. Am. J. Physiol. Gastrointest. Liver Physiol., 2012, 303 : G675-G685.
5. BAJAJ J, RIDLON J, HYLEMON P, THACKER L, HEUMAN D, SMITH S. et al. Linkage of gut microbiome with cognition in hepatic encephalopathy. Am. J. Physiol. Gastrointest. Liver Physiol., 2012, 302 : G168-G175.

6. NAVA G, STAPPENBECK T. Diversity of the autochthonous colonic microbiota. Gut Microbes, 2011, 2 : 99-104.

7. BAJAJ J. The role of microbiota in hepatic encephalopathy. Gut Microbes, 2014, $5: 397-403$.

8. ALSAHHAR J, RAHIMI R. Updates on the pathophysiology and therapeutic targets for hepatic encephalopathy. Gastroenterology, 2019, 35 : 145-154.

9. ADOLPH T, GRANDER C, MOSCHEN A, TILG H. Liver-Microbiome Axis in health and disease. Trends in Immunology, 2018, 39 : 712-723.

10. PONTE A, PINHO R, MOTA M, SILVA J, VIEIRA N, OLIVEIRA R. et al. Fecal microbiota transplantation in refractory or recurrent Clostridium difficile infection: a real-life experience in a non-academic center. Rev. Esp. Enferm. Dig., 2018, 110 : 311-315.

11. MULLISH B, QURAISHI M, SEGAL J, MCCUNE V, BAXTER M, MARSDEN E. et al. The use of faecal microbiota transplant as treatment for recurrent or refractory Clostridium difficile infection and other potential indications: joint British Society of Gastroenterology (BSG) and Healthcare Infection Society (HIS) guidelines. Gut, 2018, 0 : 1-22.

12. KELLY C, KAHN S, KASHYAP P, LAINE L, RUBIN D, ATREJA A. et al. Update on Fecal Microbiota Transplantation: Indications, Methodologies, Mechanisms and Outlook. Gastroenterology, 2015, 149 : 223-237.

13. PINN D, ARONIADIS O, BRANDT L. Is fecal microbiota transplantation the answer for irritable bowel syndrome? A single-center experience. Am. $J$. Gastroenterol., 2014, 109.

14. HOLVOET T, JOOSSENS M, WANG J, BOELENS J, VERHASSELT B, LAUKENS D. et al. Assessment of faecal microbial transfer in irritable bowel syndrome with severe bloating. Gut, 2017, 0 : 1-3.

15. EL-SALHY M, MAZZAWI T. Fecal microbiota transplantation for managing irritable bowel syndrome. Expert Review of Gastroenterology \& Hepatology, 2018, $12: 439-445$.

16. PONTE A, PINHO R, MOTA M. Fecal microbiota transplantation: is there a role in the eradication of carbapenem-resistant Klebsiella pneumoniae intestinal carriage? Rev. Esp. Enferm. Dig., 2017, 109 : 392.

17. YOON Y, SUH J, KANG E, KIM J. Efficacy and safety of fecal microbiota transplantation for decolonization of intestinal multidrug-resistant microorganism carriage: beyond Clostridioides difficile infection. Ann. Med., 2019, $51: 379-389$.

18. SAHA S, TARIQ R, TOSH P, PARDI D, KHANNA S. Faecal microbiota transplantation for eradicating carriage of multidrug-resistant organisms: a systematic review. Clin. Microbiol. Infect., 2019, 25 : 958-963.

19. BLANCHAERT C, STRUBBE B, PEETERS H. Fecal microbiota transplantation in ulcerative colitis. Acta Gastroenterol. Belg., 2019, 82 : 519528.

20. KAO D, ROACH B, PARK H, HOTTE N, MADSEN K, BAIN V. et al. Fecal Microbiota Transplantation in the Management of Hepatic Encephalopathy. Hepatology, 2016, $63:$ 339-340.

21. SANDEEP S, NOHRIA S, SIDHU S. Fecal microbiota transplantation in management of hepatic encephalopathy. Journal of Clinical and Experimental Hepatology, 2017, 7 : S56.

22. MEHTA R, KABRAWALA M, NANDWANI S, KALRA P, PATEL C, DESAI P. et al. Preliminary experience with single fecal microbiota transplant for treatment of recurrent overt hepatic encephalopathy - A case series. Indian Journal of Gastroenterology, 2018, 37 : 559-562.

23. BAJAJ J, KASSAM Z, FAGAN A, GAVIS E, LIU E, COX I. et al. Fecal Microbiota Transplant from a Rational Stool Donor Improves Hepatic Encephalopathy: A Randomized Clinical Trial. Hepatology, 66 : 1727-1738.

24. BAJAJ J, FAGAN A, GAVIS E, KASSAM Z, SIKAROODI M, GILLEVET P. Long-term Outcomes After Fecal Microbiota Transplantation in Cirrhosis. Gastroenterology, 2019, $156:$ 1921-1923.

25. BAJAJ J, SALZMAN N, ACHARYA C, STERLING R, WHITE M, GAVIS E. et al. Fecal Microbial Transplant Capsules Are Safe in Hepatic Encephalopathy : A Phase 1,Randomized, Placebo-Controlled Trial. Hepatology, 2019, 70 : 1690-1703.

26. KELLY C, IHUNNAH C, FISCHER M, KHORUTS A, SURAWICZ C, AFZALI A. et al. Fecal microbiota transplant for treatment of Clostridium difficile infection in immunocompromised patients. Am. J. Gastroenterol., 2014, 109 : 1065-1071.

27. CAMMAROTA G, IANIRO G, TILG H, RAJILIĆ-STOJANOVIĆ M, KUMP P, SATOKARI R. et al. European consensus conference on faecal microbiota transplantation in clinical practice. Gut, 2017, 0 : 1-12. 